\title{
Retalho de padrão axial da artéria torácica lateral para reconstrução de lesão cutânea em região de cotovelo de cão: Relato de caso*
}

\section{Use of lateral thoracic axial pattern flap to repair cutaneous defect in a dog elbow: Case report}

\author{
Cristhian Rene Vargas Estrada, ${ }^{* *}$ Mariana Palma Correa da Silva, ${ }^{* *}$ Suélem Lavorato Oliveira, ${ }^{* * * *}$ \\ Ana Carolina Gasques Salgado dos Santos, ${ }^{* * *}$ Rafael Ricardo Huppes, ${ }^{* * * *}$ Jorge Luiz Costa Castro, ${ }^{* * * * * *}$ \\ Bruna Costa Nonato, ${ }^{* *}$ Filippo Jannoni Lessa Bernardes, ${ }^{* * *}$ \\ Andrigo Barboza de Nardi***
}

\section{Resumo}

Os retalhos cutâneos são técnicas de escolha para reconstrução de grandes defeitos. Objetivou-se relatar o emprego do retalho de padrão axial da artéria torácica lateral em paciente com ferida cirúrgica ocasionada imediatamente após exérese de neoformação na região da articulação do cotovelo. Foi atendido paciente canino macho, 10 anos, pesando 12 kg, apresentando neoformação em tecidos moles, de grande volume, localizada na região medial do cotovelo. Como tratamento definitivo, implementou-se a exérese marginal da neoplasma seguida de reconstrução com a técnica de retalho de padrão axial da artéria torácica lateral. A técnica possibilitou completa síntese e oclusão do defeito, obtendo-se ótima recuperação pós operatória, não sendo observada deiscência de sutura ou necrose do retalho. Conclui-se que a implementação do retalho da artéria torácica lateral foi uma técnica viável na reconstrução em cotovelo após a exérese do neoplasma no paciente relatado, observando resultados satisfatórios quanto aos aspectos funcionais e cosméticos, após o período cicatricial.

Palavras-chave: Angiossoma, cirurgia reconstrutiva, retalho de padrão axial.

\begin{abstract}
Skin flaps are suitable methods of wound closure in large cutaneous defects. I The present study aims to report the use of lateral thoracic axial pattern flap to repair an elbow wound secondary to a neoplasm resection. A 10 -year-old male dog weighing $12 \mathrm{~kg}$ was presented with a large soft tissue neoplasm in the medial aspect of the elbow. The patient underwent surgical resection of the neoplasm using the lateral thoracic cutaneous flap to achieve a complete defect closure, resulting in an excellent postoperative wound healing without suture failure or skin flap necrosis. It is concluded that the implementation of the lateral thoracic artery flap was a viable technique in elbow reconstruction after neoplasm excision in the reported patient, with satisfactory results regarding functional and cosmetic aspects after the healing period.
\end{abstract}

Keywords: Angiosome, reconstructive surgery, axial pattern flap.

\section{Introdução}

Os sarcomas de tecidos moles são neoplasmas mesenquimais malignos e correspondem a cerca de 8 a $15 \%$ dos tumores cutâneos e subcutâneos dos caninos. A incidência é maior em animais idosos e em cães de médio a grande porte, não havendo predisposição racial ou sexual (JARK, P.C et al., 2017; CASTRO, P.F et al., 2019).

A principal conduta terapêutica instituída no sarcoma de tecidos moles envolve a remoção cirúrgica com amplas margens, associado a outras técnicas de controle local, como radioterapia e eletroquimioterapia. Apresentam baixas respostas ao tratamento quimioterapêutico, sendo aplicadas mais frequentemente a casos paliativos (JARK, P.C et al., 2017). O uso da quimioterapia metronômica, ciclofosfamida associada ao piroxicam, mostrou resultados interessantes na prevenção da recorrência dos sarcomas de tecidos moles (BARROS V.T.M e REPETTI, C.S.F. 2015).

As técnicas de cirurgia reconstrutiva são didaticamente classificadas em duas modalidades, os enxertos e os retalhos, sendo a última a mais utilizada. Os retalhos cutâneos são subdivididos em padrão subdérmico e padrão axial. Os retalhos

\footnotetext{
${ }^{*}$ Recebido em 30 de maio de 2021 e aceito em 22 de julho de 2021.

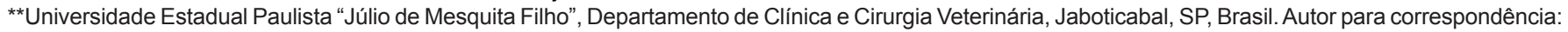
crisvaresmvz@gmail.com.

***Universidade Estadual Paulista “Júlio de Mesquita Filho”, Departamento de Clínica e Cirurgia Veterinária, Jaboticabal, SP, Brasil.

${ }^{* * * *}$ Centro Universitário das Faculdades Integradas de Ourinhos, Ourinhos, SP, Brasil.

*****Universidade Unicesumar, Departamento de Cirurgia Veterinária, Maringá, PR, Brasil.

******Pontifícia Universidade Católica do Paraná, Departamento de cirurgia veterinária da, Curitiba, PR, Brasil.
} 
de padrão axial são caracterizados por apresentarem uma artéria cutânea direta (angiossoma), permitindo a síntese de feridas extensas com ótimas taxas de sucesso (LIPTAK, J.M et al I., 2008; LOSINSKI, S.L et al., 2015).

O objetivo do presente trabalho é relatar o uso do retalho de padrão axial da artéria torácica lateral em canino com sarcoma de tecidos moles.

\section{Relato de Caso}

Foi atendido, no Serviço de Oncologia Veterinária do Hospital Veterinário da Universidade Estadual Paulista, campus de Jaboticabal, canino, macho, de 10 anos de idade, $12 \mathrm{~kg}$, sem raça definida, castrado, apresentando neoplasma cutâneo. Ao exame físico, o paciente apresentava bom estado geral e parâmetros fisiológicos normais. Observou-se a presença de um nódulo de consistência firme, bem delimitado, vascularizado, localizado na face medial da região do cotovelo, medindo $7,5 \times 6,5 \times 5,3 \mathrm{~cm}$ (Figura 1). Foram realizados exames complementares como hemograma, análise bioquímica (ALT, creatinina, ureia), urinálise, UPC, radiografia torácica (três projeções), ultrassonografia abdominal e eletrocardiograma, não evidenciando qualquer alteração digna de nota. Ainda, foi realizada citologia pelo método de punção aspirativa com agulha fina (PAAF), sendo o resultado sugestivo de neoplasia de células mesenquimais.

Figura 1: Imagem fotográfica do paciente com neoplasma em cotovelo. A) Neoplasma na região medial do cotovelo. B) Planejamento pré-operatório com a dermarçao do retalho de padrão axial da artéria torácica lateral Arquivo pessoal

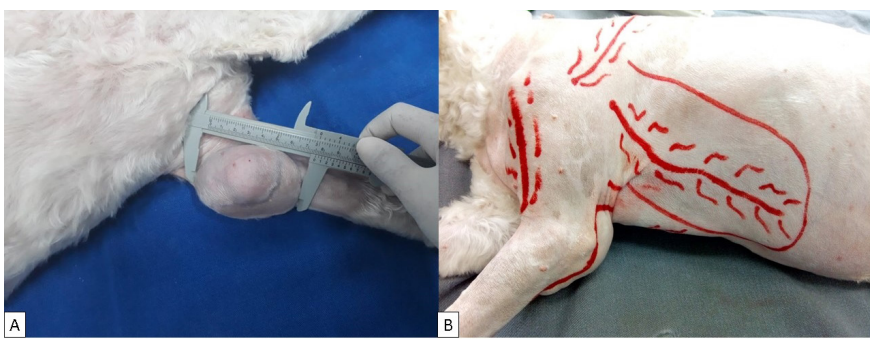

O tratamento instituído foi a exérese cirúrgica do neoplasma, utilizando como reconstrução cirúrgica o retalho de padrão axial da artéria torácica lateral com linfadenectomia axilar.

Após o manejo pré-operatório com jejum alimentar de 8 horas e hídrico de uma hora, administrou-se como medicação préanestésica acepromazina $0,2 \%$ e morfina $1 \%$, nas doses de 0,03 $\mathrm{mg} / \mathrm{kg}$ e 0,3 mg/kg, respectivamente, por via intramuscular. Após 15 minutos, procedeu-se com a tricotomia da área cirúrgica, cateterização venosa e demarcação do planejamento cirúrgico com auxílio de uma caneta cirúrgica dermográfica. Na sequência foi instituída a antibioticoterapia profilática com cefazolina, (30 mg/kg), 30 minutos antes de realizar a incisão. A indução anestésica foi realizada utilizando propofol $1 \% \quad(5 \mathrm{mg} / \mathrm{kg})$. O paciente foi intubado e mantido sob anestesia inalatória com isofluorano, com concentração alveolar mínima (CAM) de 0,6\%, vaporizado em oxigênio sob ventilação espontânea.

Posicionou-se o paciente em decúbito lateral direito com o membro torácico esquerdo em abdução com hiperextensão e realizou-se a antissepsia geral e definitiva. Foram posicionados os campos operatórios e a demarcação da cadeia linfática com aplicação de azul patente (OCTALAB DO BRASIL S/A) a 2 mg/ $\mathrm{kg}$, por via intradérmica.

Foi realizada incisão cutânea de acordo com a demarcação prévia, seguida da exérese tumoral em padrão cirúrgico marginal. Na sequência, o leito cirúrgico foi lavado com solução fisiológica a $0,9 \%$ e as luvas e o instrumental cirúrgico foram substituídos. Posteriormente, procedeu-se com a linfadenectomia axilar e incisão do retalho de padrão axial da artéria torácica lateral, previamente demarcado. A elevação do retalho foi executada por meio de dissecção dos tecidos adiposos, preservando toda a vascularização cutânea. Ato contínuo, o retalho foi transposto para o leito receptor, recobrindo o defeito cirúrgico em sua totalidade. Para o reparo do leito doador foi realizada a divulsão do tecido subcutâneo e realizadas suturas no padrão "Walking Suture", utilizando fio poliglecaprone 25, 2-0. Para a dermorrafia das bordas cutâneas, foram realizadas suturas intradérmicas com poliglecaprone 25, 3-0. Nas bordas cutâneas do leito receptor e do retalho, foram realizadas suturas em padrão simples interrompido subcuticular seguido de sutura contínua intradérmica, utilizando poliglecaprone 25 , 3-0. Não foi realizada sutura de pele no paciente (Figura 2).

Figura 2: Imagem fotográfica do pré e peri-operatório de paciente canino com sarcoma de tecidos moles. A) Observase a aplicação do azul patente para demarcação da drenagem linfática (seta). B) Após, remoção do neoplasma (seta azul) e disseção do retalho de padrão axial (seta branca). C) Observa-se a artéria torácica lateral e suas ramificações (seta). D) Imagem fotográfica do pós-operatório imediato

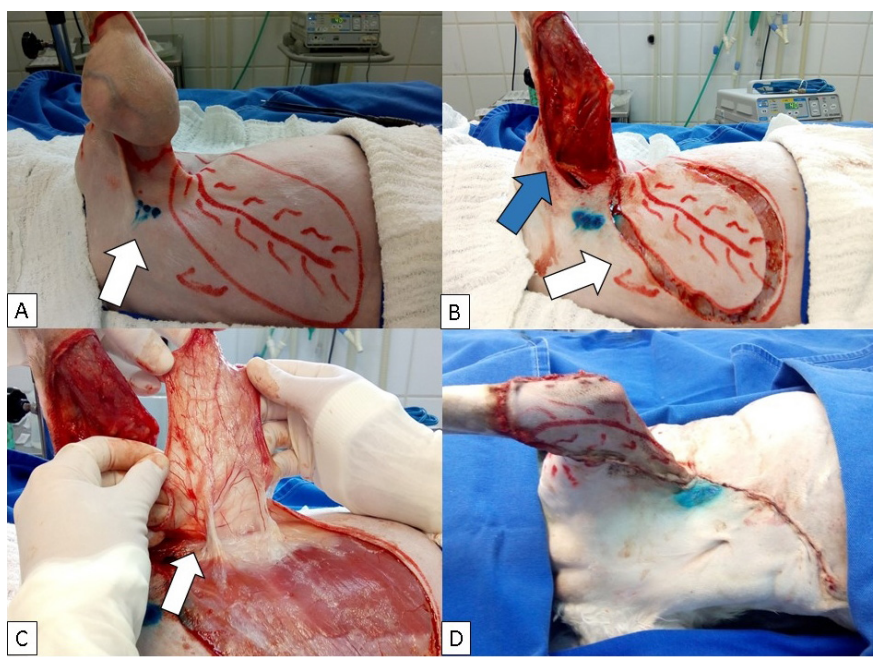

Ao fim do procedimento cirúrgico, realizou-se a administração do anti-inflamatório meloxicam $1 \%(0,1 \mathrm{mg} / \mathrm{kg})$, a limpeza da ferida cirúrgica com solução salina $0,9 \%$ associada à compressas frias, com posterior colocação de bandagem do membro torácico e da região torácica e cervical.

Para o exame histopatológico, o material biológico foi fixado em solução aquosa de formol tamponado à $10 \%$ e encaminhado ao Setor de Patologia da Universidade Estadual Paulista, resultando em sarcoma de tecidos moles grau II, sem metástase em linfonodo, com margens caudal e profunda comprometidas.

Foi prescrito como tratamento domiciliar, por via oral, cefalexina (30 mg/kg/TID/2 dias), omeprazol (1 mg/kg/BID/2 dias), cloridrato 
de tramadol (4 mg/kg/BID/7 dias), carprofeno (4,4 mg/kg/SID/7 dias) e dipirona ( $25 \mathrm{mg} / \mathrm{kg} / \mathrm{BID} / 7$ dias).

A troca da bandagem foi realizada com intervalos de 24 horas durante 4 dias, passando a intervalos de 48 horas por 8 dias e uma última após 72 horas. Durante o acompanhamento pósoperatório de 21 dias, se observou a formação de hematomas na área doadora e no retalho, sendo tratado com aplicação tópica de polissulfato de mucopolissacarídeo (HIRUDOID ${ }^{\circledR}$ ) na mesma frequência da bandagem. Não foram observados edemas, seromas ou deiscência de suturas, obtendo-se ótima recuperação final (Figura 3). Devido ao acometimento das margens cirúrgicas por células neoplásicas, sugeriu-se a realização de quimioterapia adjuvante, associada à quimioterapia metronômica, no entanto, os proprietários não autorizaram a realização do tratamento recomendado, nem a realização do exame de imunoistoquímica. Após 7 meses do procedimento cirúrgico, o paciente não apresentou recidiva tumoral

Figura 3: Imagem fotográfica do pós-operatório. A) 24 horas de pós-operatório, observa-se áreas de hematoma na área do leito doador e no retalho (setas). B) 4 dias de pós-operatório. C) 7 dias de pós-operatório. D) 30 dias pós-operatório, sem presença de hematomas ou deiscência

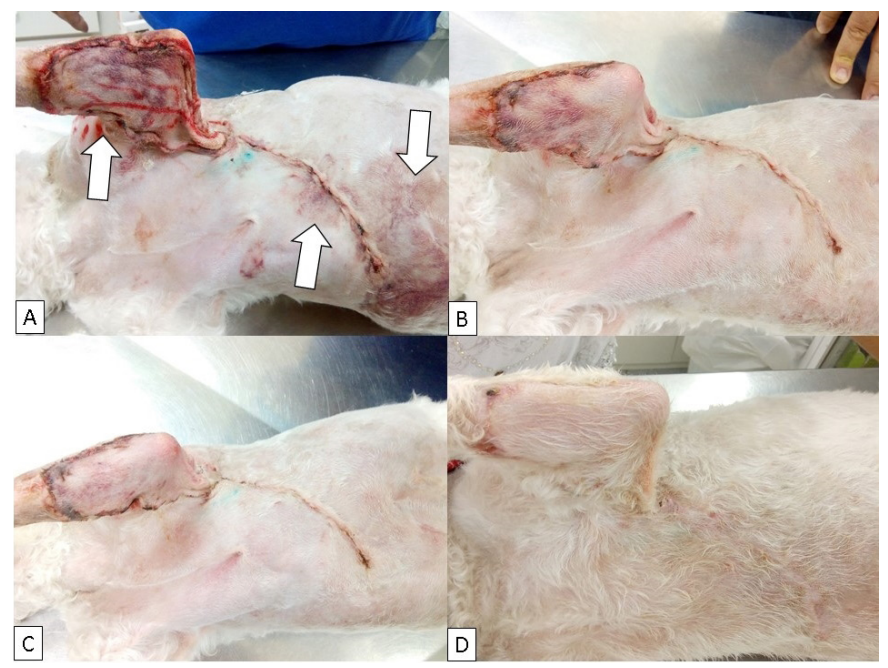

\section{Discussão}

No presente trabalho, a escolha do retalho de padrão axial da artéria torácica lateral permitiu a reconstrução tecidual da região medial do cotovelo, após exérese do neoplasma, demonstrando ser uma alternativa de técnica cirúrgica para reconstruções cutâneas desta área, em consonância com Gusmão e colaboradores (2019), que citaram que esta técnica é usada especialmente para oclusão de defeitos de região do cotovelo. No entanto, Huppes et al. (2012) descreveram que existem outras possibilidades cirúrgicas para a reconstrução de defeitos cirúrgicos na região do cotovelo, como a aplicação do retalho tubular de padrão axial da artéria tóracodorsal, permitindo o recobrimento total de lesões extensas com poucas complicações pós-operatórias. Da mesma forma, Huppes et al. (2017), relataram o uso do retalho tubular de padrão axial da artéria tóracodorsal, sendo uma ótima escolha para reconstrução da região do cotovelo, não apresentando deiscência de suturas ou necrose da extremidade do retalho.

Hedlund (2007) demonstrou que as suturas intradérmicas ou subcuticulares permitem a aposição das bordas das feridas, além de diminuírem a tensão na linha de sutura, visto que a derme suporta uma maior tensão quando comparada com o tecido subcutâneo ou até mesmo as outras camadas da pele. Como estas suturas ficam no interior da pele, os resultados cosméticos são melhores do que quando se emprega suturas externas, pontos que são levados em consideração em cirurgias reparadoras (TROUT, N.J 2003). Assim, optou-se pelo emprego dessas suturas associadas à rafia do subcutâneo, apresentando um ótimo resultado na cicatrização do paciente em questão.

Ferreira et al. (2017) descreveram a utilização do retalho de padrão axial da artéria torácica lateral em paciente com lipoma infiltrativo em área cubital. porém, o paciente apresentou hematomas, seroma e deiscência parcial de sutura. No presente trabalho, a única complicação pós-operatória foi a formação de hematomas no retalho e na região do leito doador, sem influenciar negativamente no resultado final da cicatrização . A diminuição das complicações pós-operatórias pode ser devido a utilização de polissulfato de mucopolissacarídeo (HIRUDOID ${ }^{\circledR}$ ), com o objetivo de promover o alívio da dor, redução do edema e da hiperemia.

O uso de bandagens durante o período pós-operatório, parece ter influenciado positivamente o sucesso da implementação da técnica, reduzindo complicações pós-cirúrgicas. Scheffer et al. (2013), referiram que a implementação de bandagens é necessária durante o pós-cirúrgico de pacientes que foram submetidos a cirurgias reconstrutivas, auxiliando na aderência do retalho, diminuindo o espaço morto, evitando o acúmulo de seroma e/ou infecção local.

O paciente relatado apresentava porte e idade condizentes com os citados pela literatura, sendo maior a incidência do sarcoma de tecidos moles em animais de médio a grande porte e de meia-idade a idosos (JARK, P.C et al., 2017; CASTRO, P.F et al., 2019). Mediante a realização do estadiamento clínico, foi observado que o animal não apresentava sinais metastáticos ou alterações nos exames complementares dignas de nota como descrito por Silveira (2014).

O uso isolado do exame histopatológico para diagnóstico do neoplasma em questão não proporciona dados suficientes para a graduação de fatores de malignidade, sendo necessária a realização de exames complementares, como o uso da técnica de imuno-histoquímica para diferenciação precisa e avaliação do prognóstico (DENNIS, M.M et al., 2011; GILLESPIE, $V$ et al., 2011).

O uso da quimioterapia em animais acometidos por sarcoma de tecidos moles ainda é discutido, mas como descrito por Jark P.C et al (2017) é indicada a realização dessa modalidade terapêutica em pacientes cujo resultado do exame histopatológico é de sarcomas de tecidos moles grau III ou ainda na presença de sinais de metástase. No caso descrito mesmo se tratando de um sarcoma grau II, foi recomendado o uso da quimioterapia adjuvante em virtude da presença de margens comprometidas após a exérese tumoral. 


\section{Conclusão}

Pode-se concluir que no paciente relatado o uso do retalho de padrão axial da artéria torácica lateral, apresentou viabilidade e resultado satisfatório, não ocasionando complicações pós

\section{Referências}

BARROS, V.T.M; REPETTI, C.S.F. Quimioterapia metronômica em cães: revisão de literatura. Revista Portuguesa de Ciência Veterinárias, v. 110, p. 593-594, 2015.

CASTRO P.F.et al. Sarcoma de tecidos moles em cães: a ressecção cirúrgica cura?. Revista de Educação Continuada em Medicina Veterinária e Zootecnia do CRMV-SP, v. 17, n. 2, p. 48-54, 2019.

DENNIS, M.M. et al. Prognostic factors for cutaneous and subcutaneous soft tissue sarcomas in dogs. Veterinary Pathology, v. 48, n. 1, p. 73-84, 2011.

FERREIRA, N. et al. Retalho cutâneo de padrão axial torácico lateral para reconstrução de defeito em articulação de região úmero-rádio-ulnar após a exérese de lipoma infiltrativo em cão: relato de caso. Almanaque de Medicina Veterinária e Zootecnia. v. 3, n. 1, p. 96-99, 2017.

GILLESPIE, V. et al. Canine gastrointestinal stromal tumors: immunohistochemical expression of CD34 and examination of prognostic indicators including proliferation markers Ki67 e AgNOR. Veterinary Pathology, v. 48, n. 1, p. 283-291, 2011.

GUSMÃO, B.S. et al. Técnicas de reconstrução para defeitos cutâneos em região de região úmero-rádio-ulnar. Investigação. v.18, n.1, p. 25-34, 2019.

HEDLUND, C.S. Surgery of the integumentary system. In: T.W. Fossum, Small animal surgery. St. Louis, Missouri: Mosby Inc., Elsevier Inc, 2007. p. 159-259. operatórias. No entanto, é de grande importância ressaltar a necessidade de um estudo com um número maior de pacientes implementando a técnica relatada, com a finalidade de avaliar de forma mais acurada a viabilidade do retalho em diferentes pacientes.

HUPPES, R.R. et al. Utilização de flape em padrão axial toracodorsal para reconstrução de defeitos após a ressecção de neoplasias - relato de dois casos. Jornal Brasileiro de Cirurgia Veterinária, v. 1, n. 1, p. 68-74, 2012.

HUPPES, R.R. et al. The use of tubular subdermal and axial flaps in the correction of four cases of extensive lesions. Ciência Rural, v. 47, n. 11, 2017.

JARK, P.C. et al. Sarcoma de Tecidos Moles Cutâneos e Subcutâneos em Cães. In: Daleck CR, De Nardi AB. Oncologia em cães e gatos. $2^{a}$ Edição. Rio de Janeiro: Editora Roca; 2017. p. 517-529.

LIPTAK, J.M. et al. Reconstruction of chest wall defects after rib tumor resection: a comparison of autogenous, prosthetic, and composite techniques in 44 dogs. Veterinary Surgery, 2008. p. 479-487.

LOSINSKI, S.L. et al. Versatility of the Angularis Oris Axial Pattern Flap for Facial Reconstruction. Veterinary Surgery, v. 44, n.8, p. 930-938, 2015.

SCHEFFER, J.P. et al. Cirurgia reconstrutiva no tratamento de feridas traumáticas em pequenos animais. Brazilian Journal of Veterinary Medicine, v. 35, n. 1, p. 70-78, 2013.

SILVEIRA, M.F. et al. Características epidemiológicas de sarcomas de tecidos moles caninos e felinos: levantamento de 30 anos Revista Acadêmica Ciência Animal, v. 10, n. 4, p. 361-365, 2014.

TROUT, N.J. Principles of plastic and reconstructive surgery. In D. Slatter, Textbook of small animal surgery. Philadelphia: Saunders, Elsevier Science, 2003. pp. 274-292. 